\title{
Sports Food Safety Supervision Based on AHP and Interval Fuzzy TOP- SIS
}

\author{
Huixia Sun ${ }^{*}$
}

Huanghe Science and Technology College, China

\begin{abstract}
In recent years, China's food safety problems emerge in endlessly, from the "Sanlu milk powder contains melamine", "Shuanghui contains clenbuterol", to Wal-Mart false green pork, the occurrence of these events, makes the "safe" on the tip of the tongue is more and more attention. Sports food safety supervision system is established in accordance with the Law of Food Safety in China. This is a joint system of government supervision and food trade association selfregulation. Sports food supply chain's each link is closely related to the safety of the athletes, strengthen the risk management in the process of food supply chain operation is to avoid the urgent requirements of food safety and quality accident. The implementation of accurate, comprehensive and rapid analysis of supply chain risk assessment is a key link in the process of risk management. In the paper, a methodology based on AHP (Analytic Hierarchy Process) and interval fuzzy TOPSIS (Technique for Order Preference by Similarity to Ideal Solution) is used for analyzing the safety supervision of sports foods. The proposed approach determines different suppliers and uses various criteria to rank different alternatives. The preliminary results indicate that the proposed model of this paper is capable of determining appropriate suppliers in sports food industry.
\end{abstract}

Keywords: Sports food; Safety supervision; AHP; TOPSIS; Supply chain.

\section{INTRODUCTION}

In recent years, with the rapid development of our economy, people's living level Continuously improve , our country's food industry has achieved rapid development, at the same time people has higher requirement for food [1-2]. However, food safety problems emerge in endlessly, Sudan red, cooking oil, poison capsule appalling events occur frequently, such as all kinds of food safety "door" testing the endurance of consumers, the open of the series "door", let consumers have a concern on food safety, people can't help send out such a question, "how many" door "to open in the future?" In recent years, research on supply chain risk management and risk assessment is gradually heating up. Especially the food industry which with a long supply chain and the increasing uncertainty of the supply and demand, the research of the food supply chain risk management and risk assessment is more urgent and important.

The food supply chain point to each link from primary production to consumption and operation order, includes that food and its accessories production, distribution, storage and processing (including in food production, the production of animal feed on, and the material may contact with food and raw materials production). The current studies of food supply chain mainly stay in from the Angle of the qualitative to analysis the risk factors, and puts forward some countermeasures to prevent or solve the risk. Such as Xiaolin Chen, Junwen Feng [3-4] shows that the food supply chain and the general industry supply chain is different, they think the food

*Address correspondence to these authors at the Huanghe Science and Technology College, China; Tel: +358-6-3247476; Fax: +358-6-3247457; E-mail: hunter2011@foxmail.com supply chain risk mainly includes the technology risk, information risk, coordination, quality safety risk. Liang Xing and Yanhong Zeng analyze Shenzhen has taken some measures, in order to strengthen the management of production source, to ensure the quality and safety of agricultural products (food), mainly from the following five aspects: accelerate the process of agricultural standardization; implementation the whole process supervision of inputs, establish a product traceability system, and establish agricultural production operator self-discipline mechanism, establish a sound system of agricultural product quality safety risk assessment (food). Through the analysis of the food safety problems in the process of food supply chain, Weibin Zhang and Zhenyu $\mathrm{Gu}$ put forward a method based on the EAN UCC system. By electronic food supply chain management, we can apply the RFID technology in the food safety traceability [2].

The research of supply chain risk assessment methods was started earlier at abroad, and has made some achievements. In the early risk assessment, primarily based on past experience and control of the entire supply chain to judge, with advances in technology and the generation of some new techniques and methods, in particular the development of computer technologies, scholars often use quantitative methods to study Supply chain risks, but these quantitative evaluation methods often have subjective color; at present the most used is a combination of quantitative and qualitative methods, this method can make more accurate assessment of supply chain risks [5-6].

As the supply chain risk assessment is uncertain, therefore scholars use subjective methods under normal situations. Some scholars have adopted objective methods. Subjective 
methods mainly are AHP, fuzzy evaluation method and gray evaluation method; objective methods mainly are entropy method etc. The overall risks of supply chain are composed of multiple risk fitting. Most scholars at home and abroad believe that there is a linear relationship between these different risks. The easiest way is to first determine the degree of importance that each risk weight, and then use the weighted average of the individual to synthesize an overall risk.

In the current society, with an increasing trend and complexity of information, the primary focus of industrial enterprises is to have continuous improvement. Since there is a close competition in the food industries and the market is highly competitive in this industry, many business owners in this industry have acknowledged that today's competition is the competition in the supply chain and concentrate more on SCM creates the most important sources of competitive advantage. Supply chain contains material, information and financial flows, and it can provide a good condition for increasing competitiveness.

In this study, the researchers try to investigate the SCM issue in food industries and explain that despite the success of this industry, the relationship among different SC parties is very complex and challenging. For food companies, there are many weaknesses in this area and still there is much space for improving the SC in the mentioned companies. On one hand, the platform and modular strategy Build to order (BTO) cause to establish more opportunities with higher profit margin in business and on the other hand, this procedure causes to move towards strengthening more need to pure management and integration of expanded supply chain (on the global scale).

Now, many systems to measure the supply chain performance are not adequate because these measurements strongly rely on the use of cost as a major step, they are by no means comprehensive, they are often in conflict with the organization's strategic objectives and finally do not consider the effects of uncertainty. In this study, in addition to industry analysis, it is trying to design a model for supplier selection using Multi Criteria Decision Making Method and fuzzy approach.

Through providing this model, this study attempts to show that supply chain strategy has better financial yield than the other positive key aspects (each of the other strategies) by the optimal choice of suppliers. This study is intended not only to reduce costs by providing the above model, but also to increase organization profit. In addition, the objective of this study is to show that good design of supplier selection in the food industries supply chain can improve all levels of the food industry and help to increase supply chain performance. In this research, the following questions are proposed for discussion:

(1) What are the most important criteria of considering the suppliers important in sports food industries?

(2) How could we rank the factors influencing the choice of suppliers in sports food industries supply chain?

\section{RELATED WORKS}

\subsection{Sports Food Supply Chain}

Sports food supply chain management has the obligation of integrating organizational units along the SC and synchronization of material, information and financial flows in order to meet the customer demands with the aim of improving competitiveness.

A comparative study of food supply chain strategic program with other documents helps us use its achievements. On the other hand, it makes this program understandable for people who have seen those documents. In case the inspected document is an official document, a comparative study shows that the program is compatible with the official decisions and their contents or not.

There are different rules and regulations on food industry and one of the most important upstream documents in the food products supply chain includes constitution, the prospect of twenty years, general policies and the Fifth Development Program Law. The objectives and strategies of this program are in line with the contents of the upstream documents. This program explains the upstream documents more carefully and attaches to its performance. In other words, executing this program is executing the upstream documents.

General Policies generally contain provisions for food products supply chain, but a policy in relation to the food industry has not been issued clearly. Some provisions of the general policy in revising consumption patterns are devoted to bread. One of the most important strategies to revise the bread consumption pattern is to produce bread at home. Some of the points expressed in this study are relevant to the food products supply chain.

Food supply chain activities can be divided into four sections including: 1) Farming, hunting, fishing, 2) Packaging, storage, processing, 3) Distribution and 4) Final preparation for consumption. The boundary of food products supply chain includes packaging, storage and processing (including activities which are located in code 15 in ISIC prioritizing) and to some extent, distribution and trade (domestic and international) of food products.

\subsection{Sports Food Safety Supervision}

Now we review articles and studies, which have performed in the field of food products supply chain. studied establishing the holistic modeling, which include the developed supply chain enterprise in a strategic. Holistic modeling was recognized first by the industry and more recently by the scientific communities. Decision making strategy needs comprehensive models to guide them in effective decision makings that increase the profitability of entire chain.

Determination of the optimal network configuration, inventory management policies, supply contracts, distribution strategies, supply chain integration, provision strategies and finding supply sources out of the company (using another company to supply), product design and information technology are primary examples of strategic decision makings that affects the ability of long-term profitability of the entire 
supply chain. Sharifi et al. used a methodology of system dynamics (dynamic systems) as a tool for modeling and analyzing with regard to strategic issues for food of supply chains. They provided a strategy for methodology and then examined its improvement for strategic modeling of one or more columns supply chains. Finally, they analyzed the key issue of strategic supply chain management in-depth where one of them is long-term capacity planning and in particular. They studied the capacity planning strategy for the management of food chains with the unstable limitations of deadline and with market parameters and finally, they showed the executive feasibility of the developed methodology on a network of several major chain of fast food.

\subsection{Analytical Hierarchy Process (AHP)}

AHP is a combination of qualitative and quantitative analysis proposed by operational research experts staying at the University of Pittsburgh in the mid-1970s. The basic principle of AHP is to divide the target into several levels through the relationship between its various indicators, the same level indicators have the same degree, and different levels have a certain affiliation. AHP calculation is relatively simple, and the finally obtained results are the relative weight of each indicator of the target layer.

The advantage of AHP is the combination of the qualitative analysis and quantitative calculation, which can not only reflect the advantage of qualitative analysis, and has the advantage of quantitative analysis; while using the perspective of system, analyze from an overall view, so that it can grasp the overall situation, with a very broad application space. The disadvantage of AHP is also evident, mainly in the weight index of judgment matrix, affected by experts' subjective relatively largely, and sometimes the judgment matrix does not meet the consistency.

\subsection{TOPSIS Method}

TOPSIS (Technique for Order Preference Similarity to Solution, the ideal solution Ideal by approximation) method is a relatively simple risk assessment methods. The basic principle is: to sort the possible optimal value and the worst value, and then calculate the distance between the evaluation object and the optimal value (the ideal solution) and the worst value (negative ideal solution) separately, obtain the relative closeness extent of the evaluation object and the optimal value (ideal solution), as a basis for the evaluation of the pros and cons. Advantages of TOPSIS evaluation method is that the distribution of data, the number of samples and targets are not limited, the calculation process is not very complicated, this method has an application range as wide as AHP. The disadvantage is that you need to determine the weight, with a certain degree of subjectivity and arbitrariness, while the determination of ideal solution and negative ideal solution is largely affected by evaluation conditions, besides this approach will also result in information duplication between the relationships of evaluation indicators.

\subsection{The Principal Component Analysis}

The theory of principal component analysis is mathematical transformation. Through a linear transformation it scat- ters a set of variables so that they no longer have relationships. Then sort them according to the relative variance in descending order, this arrangement will determine the merits of a variety of indicators. The advantage of principal component analysis is the weight of each factor is determined by the size of the contribution rate to avoid the interference of human factors. The disadvantage is that the calculation process is cumbersome, and it requires a larger number of samples, it is not suitable for the risk evaluation system with a small number of indicators, in addition, this method is based on the sample index attribute to make a comprehensive evaluation, so the evaluation results are largely affected by the number of samples.

\subsection{Gray Comprehensive Evaluation Association}

Gray comprehensive evaluation association is also a common supply chain risk assessment method that uses the size of the correlation with the optimal solution to sort the evaluation factors. First find out the correlation coefficient matrix made up by the feasible solutions and the ideal solution, then get the correlation degree through the correlation coefficient matrix, and finally sort according to the size of the correlation to determine the weight of each factor. This calculation method is relatively simple, can be directly calculated with the original data, and does not need to analyze a large number of sample data. Its disadvantage is that the results will be affected by the elements of the judgment matrix and appear the phenomenon of multiple solution. In addition, the correlation is always positive. The relationship between things is a positive correlation in the actual case, so that negative correlation between data will be lost.

In summary, there are a lot of methods for supply chain risk assessment. While solving the model, each method has different considering focus, so different evaluation methods may lead to different results of the evaluation.

\subsection{Multi-criteria Decision Making}

These days, most decision making problems are involved optimization of more than one single objective. In many cases, decision makers are faced with various criteria, which are also in conflict with each other. Multi-Attribute Decision Makings, also called Multi-Criteria Evaluation, assume that the decision space is discrete. Although there is no optimal solution for this problem but with a limited set of options, the aim is selecting the best option based on multiple attributes.

Technique for Order Preference by Similarity to Ideal Solution (TOPSIS) method is also one of those useful multicriteria decision making method for surveying issues in real world raised by Hwang \& Yoon (1981) for the first time. This method was also suggested by Jahanshahlo et al. They described it as:

Let $A_{1}, A_{2}, \ldots, A_{m}$ be $m$ alternatives, which are supposed to be ranked by $k_{\text {decision makers based on }} n_{\text {criteria }} C_{1}$, $C_{2}, \ldots, C_{n}$ ). Let $X_{i j}$ be the rating score of $A_{i}$ associated 
with $j_{\text {criteria and is defined as }}^{\text {th }} x_{i j} \in\left[x_{i j}^{l}, x_{i j}^{u}\right]$. Weights of criteria are defined as $w_{1}, w_{2}, \ldots, w_{n}$, where $w_{j}$ is the weight of $C_{j}$. We can define an MADM problem with interval numbers briefly in a decision making matrix.

In TOPSIS method with interval numbers we have to normalize decision making matrix as we show it below:

$$
d_{i j}=\frac{x_{i j}^{l}}{\sqrt{\sum_{j=1}^{m}\left[\left(x_{i j}^{l}\right)^{2}+\left(x_{i j}^{u}\right)^{2}\right]}}, i=1,2, \ldots, n, j=1,2, \ldots, m
$$

$$
8 u=\frac{x_{i j}^{u}}{\sqrt{\sum_{j=1}^{m}\left[\left(x_{i j}^{l}\right)^{2}+\left(x_{i j}^{u}\right)^{2}\right]}}, i=1,2, \ldots, n, j=1,2, \ldots, m
$$

Now $\left[x_{i j}^{l}, x_{i j}^{u}\right]$ are normalized and the calculated domain $\left[a_{i j}^{l}, a_{i j}^{u}\right]_{\text {belongs to }[0,1] \text {. Because of the differences in im- }}$ portance of each criterion, in the next step we will calculate weighted normalized decision matrix with interval numbers as below:

$$
\begin{aligned}
& \vartheta_{i j}=w_{j} \partial_{i j}, i=1,2, \ldots, n, j=1,2, \ldots, m \\
& \vartheta_{i j}=w_{j} \partial_{i j}, i=1,2, \ldots, n, j=1,2, \ldots, m
\end{aligned}
$$

where $w_{i}$ is the weight of the $i^{\text {th }}$ criterion and $\sum w_{i}=1$.

\subsection{Fuzzy Set}

Fuzzy set is an extended form of classic set introduced by Zadeh. In a classic set, each element has two values. In other words, an element either belongs to a set or not. If an element becomes a member of set $\mathrm{A}$, its related value is equal to 1 , and zero, otherwise. However, fuzzy theory is attributing a number between $[0,1]$ each $x$ from $X$.

A Convex Fuzzy Set: The "A" fuzzy set is convex if and only if for each $x_{1}, x_{2} \in X$ and each $\lambda \in[0,1]$, we have

$\mu_{A}\left[\lambda x_{1}+(1-\lambda) x_{2}\right] \geq \min \left[\mu_{A}\left(x_{1}\right), \mu_{A}\left(x_{2}\right)\right]$

For real-world applications, we utilize some fuzzy and vague statements rather than some crisp terms. Very low, low, middle, high and very high are some examples of linguistic terms. Fuzzy numbers can stand for these linguistic terms in a mathematical model. In this paper, the importance weights of the ratings of qualitative criteria are considered as linguistic variables. In this paper, the decision-makers use the linguistic variables shown in Table $\mathbf{1}$ to evaluate the ratings of alternatives with respect to qualitative criteria.

In this article, we select a supplier that has the low amount of risk in relationship with the company. This prob- lem can be defined as a group MADM (GMADM) problem. We consider some steps for modeling these cases as below:

a) A set of $\mathrm{k}$ decision maker that is defined by $D=\left\{D_{1}, D_{2}, \ldots, D_{k}\right\}$;

b) A set of $\mathrm{m}$ supplier (alternative) that we call it $A=\left\{A_{1}, A_{2}, \ldots, A_{m}\right\}$;

c) A set of $\mathrm{n}$ criteria that we evaluate suppliers by those criteria and call it $C=\left\{C_{1}, C_{2}, \ldots, C_{n}\right\}$;

d) A set of performance rate of supplier, $A_{i}(i=1,2, \ldots, m)$ in association with criteria $\left(C_{j}, j=1,2, \ldots, n\right)$ that we show it as $X=\left\{x_{i j}, i=1,2, \ldots, m, j=1,2, \ldots, n\right\}$

Consider a situation where there are $k$ decision makers in a group and each decision maker $D_{k \text { and }} k=1,2, \ldots, k$ evaluates suppliers based on fuzzy numbers $\mu_{\alpha^{\prime}}(x)$ that has a membership degree $\mu_{\AA 0}(x)$. After choosing adequate linguistic terms for ranking suppliers and translating them to fuzzy numbers, we utilized $\alpha$-cut method to alternate these fuzzy numbers by interval numbers instead of defuzzification for prioritizing alternatives and then we used a TOPSIS method to rank interval numbers for ranking suppliers.

\section{RESEARCH METHODOLOGY AND RESULTS}

To analyze the obtained data and select the best supplier among the available suppliers, the TOPSIS method is used. TOPSIS model was introduced by Hwang and Yoon. This model is one of the best models of multi-attribute decision making models and it is used a lot. In this method, options are evaluated by $\mathrm{n}$ attributes, too. This technique is based on this concept that the selected option shall have the minimum distance from the positive ideal solution (the best possible) and the maximum distance from the negative ideal solution (the worst possible). It is assumed that the utility of each attribute is steadily increasing or decreasing. The following tables are showing the calculated results from solving the model based on mentioned steps in TOPSIS Method.

Decision matrix gained from the average of experts' judgments is summarized in Table 2.

As can be seen, Karimi meat and poultry meat production, packaging and distribution that is the oldest producer of meat and poultry meat in Iran, has the highest weight and rank. This indicates that from the decision makers' point of view, long-term cooperation and collaboration with this supplier can make a better future for the factory. The second supplier, Fakharan meat and poultry distribution company, has a good share in the market. The last level is also associated with the meat and poultry cooperative of the province. Factory managers are not willing to be dependent to the state suppliers and prefer to deal with private suppliers. 
Table 1. Judgments of Experts about Criteria.

\begin{tabular}{|c|c|c|c|c|c|}
\hline $\mathrm{C}_{1}$ & $(0.9,0.9,1.1)$ & $\mathrm{VH}$ & $(0.7,0.8,0.9)$ & $\mathrm{H}$ & 0.4 \\
\hline $\mathrm{C}_{2}$ & $(0.9,0.9,1.1)$ & M & $(0.9,0.9,1.0)$ & $\mathrm{VH}$ & 0.6 \\
\hline $\mathrm{C}_{3}$ & $(0.9,0.9,1.1)$ & $\mathrm{VH}$ & $(0.9,0.9,1.0)$ & VH & 0.8 \\
\hline $\mathrm{C}_{5}$ & $(0.7,0.8,0.9)$ & $\mathrm{H}$ & $(0.0,0.1,0.2)$ & VL & 0.2 \\
\hline $\mathrm{C}_{6}$ & $(0.4,0.5,0.6)$ & M & $(0.4,0.5,0.6)$ & $\mathrm{H}$ & \\
\hline
\end{tabular}

According to the results, it is recommended to plant managers and decision makers, to have interaction with suppliers based on a prioritized list of suppliers and this could guarantee the long-term interaction and profitability for the company. Supplier is one of the essential elements of supply chain and its selection needs comprehensive assessment. The current method used in this company is not an accurate and documented method and sometimes causes personal opinions involve in the selection of suppliers and cause to appear a problem in the supply chain targets. Therefore, the evaluation and selection of suppliers in this company needs a system that has pre-determined criteria and follows certain principles of selection and decision making. In the proposed method, it is tried to apply the criteria and opinions of the managers in order to draw a secure pattern to select the supplier.

At the end, in addition to the above matters that can be suggested for future research, there is an issue that many companies deal with it and this issue is having a managerial approach towards the supplier selection. In fact, it is important that we cannot have a quantitative approach towards the issue and the quantitative approach cannot fulfill the needs of the managers, solely, is an issue that is seen in the current position of the industry clearly in Table $\mathbf{3}$. Therefore we recommend to discuss other issues, such as how to interact with partners and suppliers, how to form relationships with suppliers based on supply chain.

\section{RESULTS}

In the paper, a methodology based on AHP (Analytic Hierarchy Process) and interval fuzzy TOPSIS (Technique for Order Preference by Similarity to Ideal Solution) is used for analyzing the safety supervision of sports foods. The proposed approach determines different suppliers and uses various criteria to rank different alternatives. The preliminary results indicate that the proposed model of this paper is capable of determining appropriate suppliers in sports food industry.

Effective supply chain management is critical to ensuring food safety. As such, the Chinese government is aiming to address food safety issues in every link of the supply chain, from farms to dining tables. US companies, leaders in supply chain management, can assist the government in their efforts to ensure food safety by bringing best practices and international standards in supply chain management to their Chinese operations. For example, US companies practice risk management or mitigation approaches that reduce or eliminate risks in their supply chains, and domestic companies

Table 2. Decision Matrix Gained from Experts' Judgments.

\begin{tabular}{|c|c|c|c|}
\hline & $\mathrm{A}_{1}$ & $\mathrm{~A}_{2}$ & $\mathrm{~A}_{3}$ \\
\hline $\mathrm{C}_{1}$ & $(4,5,5,6)$ & $(2,3,4,5)$ & $(4,5,5,6)$ \\
\hline $\mathrm{C}_{2}$ & $(4,5,5,6)$ & $(2,3,4,5)$ & $(4,5,5,6)$ \\
\hline $\mathrm{C}_{3}$ & $(4,5,5,6)$ & $(4,5,5,6)$ & $(4,5,5,6)$ \\
\hline $\mathrm{C}_{4}$ & $(4,5,5,6)$ & $(5,6,7,8)$ & $(4,5,5,6)$ \\
\hline $\mathrm{C}_{5}$ & $(5,6,7,8)$ & $(5,6,7,8)$ & $(2,3,4,5)$ \\
\hline $\mathrm{C}_{6}$ & $(5,6,7,8)$ & $(4,5,5,6)$ & $(1)$ \\
\hline
\end{tabular}


Table 3. Final Rank of Suppliers.

\begin{tabular}{|c|c|c|}
\hline Karimi meat and poultry meat production & $\mathrm{A}_{2}$ & 0.643 \\
\hline Fakharan meat and poultry distribution company & $\mathrm{A}_{3}$ & 0.623 \\
\hline Baharan meat and poultry distribution company & $\mathrm{A}_{4}$ & 0.512 \\
\hline Goushtiran meat and poultry distribution company & $\mathrm{A}_{1}$ & 0.495 \\
\hline The meat and poultry distribution of province & $\mathrm{A}_{5}$ & 0.401 \\
\hline
\end{tabular}

could model their own supply chains on such examples. US companies can also provide valuable expertise as China formulates new rules and regulations for enhancing sports food safety.

The year 2011 saw much improvement in China's regulatory framework for ensuring safety and quality of China's food products. Both central and local governments have exerted great effort to ensure food safety, adjusting administrative structure and building the right organizational capacity.

However, deficiencies remain with regard to consistency and coordination in interpretation of regulations and national standards, generating confusion and impacting normal business operations. Efforts to improve supply chain management, clarify standards, and ensure IPR protection would create a better environment for ensuring food safety.

The increasingly global nature of supply chains mean that food safety concerns in China are also food safety concerns for US consumers. As such, the US government should continue to engage the Chinese government at a high level on food safety issues, and provide expanded resources for the US Food and Drug Administration (FDA) to collaborate with Chinese counterparts on food safety.

\section{CONFLICT OF INTEREST}

The authors confirm that this article content has no conflicts of interest.

\section{ACKNOWLEDGEMENTS}

This work is supported by the Key Project of Guangxi Social Sciences, China (No.gxsk201424), the Education Science fund of the Education Department of Guangxi, China (No.2014JGA268), and Guangxi Office for Education Sciences Planning, China (No.2013C108).

\section{REFERENCES}

[1] N. Aissaoui, M. Haouari, and E. Hassini, "Supplier selection and order lot sizing modeling: A review," Computers \& Operations Research, vol.34, no.12, pp.3516-3540, 2007.

[2] J. Choi, S.X. Bai, J. Geunes, and H.E. Romeijn, "Manufacturing delivery performance for supply chain management," Mathematical and Computer Modelling, vol.45, pp.11-20, 2007.

[3] S. Y. Chou, Y. H. Chang, "A decision support system for supplier selection based on a strategy-aligned fuzzy SMART approach," Expert System with Applications, vol.34, pp.2241-2253, 2008.

[4] M. Dagdeviren, and I. Yuksel, "Developing a fuzzy analytic hierarchy process (AHP) model for behavior-based safety management," Information Sciences, vol.178, no.6, pp.1717-1733, 2008.

[5] S. M. A. K. Firouzabadi, B. Henson, and C. Barnes, "A multiple stakeholders' approach to strategic selection decisions," Computers and Industrial Engineering, vol.54, no.4, pp.851-865, 2008.

[6] X. Chen, A. Cakravastia, and K. Takahashi, "Integrated model for supplier selection and negotiation in a make-to-order environment," International Journal of Production Research, vol.42, no.21, pp. 4457-4474, 2004. 